\title{
Editorial: Turning the Mind's Eye Inward: The Interplay Between Selective Attention and Working Memory
}

\author{
Elger Abrahamse ${ }^{1 *}$, Steve Majerus ${ }^{2}$, Wim Fias ${ }^{1}$ and Jean-Philippe van Dijck ${ }^{1}$ \\ ${ }^{1}$ Department of Experimental Psychology, University of Ghent, Ghent, Belgium, ${ }^{2}$ Department of Psychology, University of \\ Liège, Liège, Belgium
}

Keywords: working memory, selective attention, short-term memory, long-term memory, executive function

\section{OPEN ACCESS}

Edited and reviewed by: Hauke R. Heekeren,

Freie Universität Berlin, Germany

${ }^{*}$ Correspondence:

Elger Abrahamse

elger.abrahamse@ugent.be

Received: 01 August 2015 Accepted: 26 October 2015

Published: 10 November 2015

Citation:

Abrahamse E, Majerus S, Fias W and van Dijck J-P (2015) Editorial: Turning

the Mind's Eye Inward: The Interplay

Between Selective Attention and

Working Memory.

Front. Hum. Neurosci. 9:616.

doi: 10.3389/fnhum.2015.00616
Working memory refers to an intriguing and essential problem in cognitive science: How does the brain succeed in maintaining information for certain duration and perform mental operations on the stored information? An important avenue in tackling this issue stems from the relatively well-defined domain of selective attention. The role of selective attention in working memory has become increasingly dominant over the last decades as information stored in working memory has been shown to modulate (external) selective attention processing-and vice versa (for reviews see e.g., Awh and Jonides, 2001; Kiyonaga and Egner, 2013). Indeed, whereas attentional components in traditional working memory models typically relate to executive mechanisms assumed to control and supervise dedicated working memory buffers (e.g., Baddeley and Hitch, 1974; Baddeley, 2000), more recent models envisage working memory as directly and specifically emerging from selective attention turned to long-term memory representations (e.g., Cowan, 1999; Oberauer, 2009).

Despite the prominent role that selective attentional models of working memory play in current cognitive science, there is still much work to do in determining the precise implications of these models for specific aspects and characteristics of working memory-in both healthy and neuropsychological populations. The current Research Topic in Frontiers in Human Neuroscience aims to contribute to this challenge and offers novel empirical observations, state-of-the-art reviews, and intriguing theoretical proposals that illuminate the interplay between selective attention and working memory. In general, these contributions can be categorized into three broad classes of studies:

First, the majority of the papers involve empirical or theoretical efforts directly aimed at a better understanding of the interplay between selective attention and working memory. Camos and Barrouillet (2014) review the literature and identify attentional and non-attentional mechanisms that contribute to the maintenance of information in verbal working memory. Vergauwe and Cowan (2014) conclude on the basis of a review that attentional search within working memory happens at a high-speed processing rate of about $35-40 \mathrm{~ms}$ per item, and propose that this rate reflects the involvement of gamma oscillations in the brain. Pedale and Santangelo (2015) investigated to what degree sensory saliency of the item information during encoding modulates the current contents of WM during recollection. van Moorselaar et al. (2015) focus on the reverse relationship and investigate the time course in which information in working memory is protected against interfering visual input. Zokaei et al. (2014) tackle an outstanding question about the representational state of items in working memory that are not prioritized by attentional focusing. Abrahamse et al. (2014) hypothesize that serial order coding in verbal working memory appeals to the spatial attention system and thereby can be synthesized with selective attentional models on working memory in general. Ginsburg and Gevers (2015) conclude from their experiments that serial order in working memory and long-term memory both drive spatial effects but differentially so. De Fockert and Leiser (2014) tackle the relationship between working memory functioning 
and executive attention and wonder whether the lack of available working memory resources can in some situations enhance information processing. By reviewing the literature, Vandierendonck (2014) elaborates on the link between executive attention and selective attention and proposes a symbiotic model in which their close relationship is stressed. Relatedly, Kiyonaga and Egner (2014) investigate to what degree interactions between external attention and attention in working memory depend on shared attentional resources. Quak et al. (2015) extend these issues by emphasizing the need for a multisensory approach to working memory, and list a number of potential starting points.

Second, the study of the interplay between selective attention and working memory is not only fruitful for increasing our understanding of the cognitive underpinnings of working memory, it also helps us to achieve a better understanding of specific cognitive and behavioral difficulties across various types of populations. Holmes et al. (2014) demonstrate this to be the case for children with $\mathrm{ADHD}$ and children with low working memory capacity. In a similar vein Wong et al. (2015) show that this approach is also helpful to describe the subtle cognitive characteristics associated with specific genetic variations, such as the fragile X premutation. Roome et al. (2014) propose and show how the bisectioning of working memory into various (attentional and other) components can help to better understand the (normal) development of working memory.

Third, the current Research Topic also contains studies that extrapolate insights from the interplay between selective

\section{REFERENCES}

Abrahamse, E., van Dijck, J.-P., Majerus, S., and Fias, W. (2014). Finding the answer in space: the mental whiteboard hypothesis on serial order in working memory. Front. Hum. Neurosci. 8:932. doi: 10.3389/fnhum.2014. 00932

Awh, E., and Jonides, J. (2001). Overlapping mechanisms of attention and spatial working memory. Trends Cogn. Sci. 5, 119-126. doi: 10.1016/S13646613(00)01593-X

Baddeley, A. (2000). The episodic buffer: a new component of working memory? Trends Cogn. Sci. 4, 417-423. doi: 10.1016/S1364-6613(00)01538-2

Baddeley, A. D., and Hitch, G. (1974). "Recent advances in learning and motivation," in Working Memory, Vol. 8, ed G. A. Bower (New York, NY: Academic Press), 647-667.

Camos, V., and Barrouillet, P. (2014). Attentional and non-attentional systems in the maintenance of verbal information in working memory: the executive and phonological loops. Front. Hum. Neurosci. 8:900. doi: 10.3389/fnhum.2014.00900

Cowan, N. (1999). “An embedded-processes model of working memory," in Models of Working Memory: Mechanisms of Active Maintenance and Executive Control, eds A. Miyake and P. Shah (New York, NY: Cambridge University Press), $62-101$.

De Fockert, J. W., and Leiser, J. (2014). Better target detection in the presence of collinear flankers under high working memory load. Front. Hum. Neurosci. 8:821. doi: 10.3389/fnhum.2014.00821

Ginsburg, V., and Gevers, W. (2015). Spatial coding of ordinal information in short- and long-term memory. Front. Hum. Neurosci. 9:8. doi: 10.3389/fnhum.2015.00008

Holmes, J., Hilton, K. A., Place, M., Alloway, T. P., Elliott, J. G., and Gathercole, S. E. (2014). Children with low working memory and children with ADHD: same or different? Front. Hum. Neurosci. 8:976. doi: 10.3389/fnhum.2014. 00976 attention and working memory to other domains. For example, Meghanathan et al. (2015) investigate whether the availability of working memory resources can be predicted from oculometric parameters, such as eye fixation duration and pupil size. Moreover, Tanaka et al. (2014) use eye-tracking methodology to investigate to what degree individual differences in working memory capacity are predictive of word relocation processes during reading.

Overall, we are convinced that the studies in the current Research Topic provide much food for thought, as well as inspiration to keep up the empirical work on the interplay between selective attention and working memory. We would explicitly like to thank all the authors for their contributions as well as the reviewers for their critical reading.

\section{ACKNOWLEDGMENTS}

EA was supported by Research Foundation Flanders under contract number $12 \mathrm{C} 4715 \mathrm{~N}$. SM was supported by grants F.R.S.-FNRS N ${ }^{\circ}$ 1.5.056.10 (Fund for Scientific Research FNRS, Belgium), and ARC 12/17/01 REST (Université de Liège). WF was supported by the Ghent University Multidisciplinary Research Partnership "The integrative neuroscience of behavioral control," and a GOA grant of Ghent University. SM and WF were supported by PAI-IUAP P7/11 (Belgian Science Policy).

Kiyonaga, A., and Egner, T. (2013). Working memory as internal attention: toward an integrative account of internal and external selection processes. Psychon. Bull. Rev. 20, 228-242. doi: 10.3758/s13423-0120359-y

Kiyonaga, A., and Egner, T. (2014). Resource-sharing between internal maintenance and external selection modulates attentional capture by working memory content. Front. Hum. Neurosci. 8:670. doi: 10.3389/fnhum.2014.00670

Meghanathan, R. N., van Leeuwen, C., and Nikolaev, A. R. (2015). Fixation duration surpasses pupil size as a measure of memory load in free viewing. Front. Hum. Neurosci. 8:1063. doi: 10.3389/fnhum.2014.01063

Oberauer, K. (2009). “Design for a working memory," in Psychology of Learning and Motivation: Advances in Research and Theory, Vol. 51, ed B. H. Ross (San Diego, CA: Elsevier Academic Press Inc), 45-100.

Pedale, T., and Santangelo, V. (2015). Perceptual salience affects the contents of working memory during free-recollection of objects from natural scenes. Front. Hum. Neurosci. 9:60. doi: 10.3389/fnhum.2015.00060

Quak, M., London, R. E., and Talsma, D. (2015). A multisensory perspective of working memory. Front. Hum. Neurosci. 9:197. doi: 10.3389/fnhum.2015.00197

Roome, H. E., Towse, J. N., and Jarrold, C. (2014). How do selective attentional processes contribute to maintenance and recall in children's working memory capacity? Front. Hum. Neurosci. 8:1011. doi: 10.3389/fnhum.2014.01011

Tanaka, T., Sugimoto, M., Tanida, Y., and Saito, S. (2014). The influences of working memory representations on long-range regression in text reading: an eye-tracking study. Front. Hum. Neurosci. 8:765. doi: 10.3389 /fnhum.2014.00765

Vandierendonck, A. (2014). Symbiosis of executive and selective attention in working memory. Front. Hum. Neurosci. 8:588. doi: 10.3389/fnhum.2014. 00588

van Moorselaar, D., Gunseli, E., Theeuwes, J., and Olivers, C. N. L. (2015). The time course of protecting a visual memory representation from perceptual interference. Front. Hum. Neurosci. 8:1053. doi: 10.3389/fnhum.2014. 01053 
Vergauwe, E., and Cowan, N. (2014). A common short-term memory retrieval rate may describe many cognitive procedures. Front. Hum. Neurosci. 8:126. doi: 10.3389/fnhum.2014.00126

Wong, L. M., Tassone, F., Rivera, S. M., and Simon, T. J. (2015). Temporal dynamics of attentional selection in adult male carriers of the fragile $\mathrm{X}$ premutation allele and adult controls. Front. Hum. Neurosci. 9:37. doi: 10.3389/fnhum.2015.00037

Zokaei, N., Ning, S., Manohar, S., Feredoes, E., and Husain, M. (2014). Flexibility of representational states in working memory. Front. Hum. Neurosci. 8:853. doi: 10.3389/fnhum.2014.0085
Conflict of Interest Statement: The authors declare that the research was conducted in the absence of any commercial or financial relationships that could be construed as a potential conflict of interest.

Copyright (c) 2015 Abrahamse, Majerus, Fias and van Dijck. This is an open-access article distributed under the terms of the Creative Commons Attribution License (CC $B Y)$. The use, distribution or reproduction in other forums is permitted, provided the original author(s) or licensor are credited and that the original publication in this journal is cited, in accordance with accepted academic practice. No use, distribution or reproduction is permitted which does not comply with these terms. 